\title{
Thermal Gradient Effects On Thirteen Flush Mounted Pressure Transducers
}

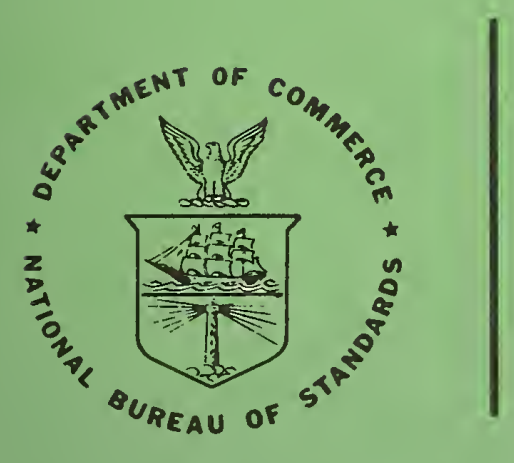

U.S. DEPARTMENT OF COMMERCE National Bureau of Standards 


\section{NATIONAL BUREAU OF STANDARDS}

The National Bureau of Standards ' was established by an act of Congress March 3, 1901. Today, in addition to serving as the Nation's central measurement laboratory, the Bureau is a principal focal point in the Federal Government for assuring maximum application of the physical and engineering sciences to the advancement of technology in industry and commerce. To this end the Bureau conducts research and provides central national services in four broad program areas. These are: (1) basic measurements and standards, (2) materials measurements and standards, (3) technological measurements and standards, and (4) transfer of technology.

The Bureau comprises the Institute for Basic Standards, the Institute for Materials Research, the Institute for Applied Technology, the Center for Radiation Research, the Center for Computer Sciences and Technology, and the Office for Information Programs.

THE INSTITUTE FOR BASIC STANDARDS provides the central basis within the United States of a complete and consistent system of physical measurement; coordinates that system with measurement systems of other nations; and furnishes essential services leading to accurate and uniform physical measurements throughout the Nation's scientific community, industry, and commerce. The Institute consists of an Office of Measurement Services and the following technical divisions:

Applied Mathematics-Electricity-Metrology-Mechanics-Heat-Atomic and Molecular Physics-Radio Physics "-Radio Engineering "-Time and Frequency 2-Astrophysics "-Cryogenics. ${ }^{2}$

THE INSTITUTE FOR MATERIALS RESEARCH conducts materials research leading to improved methods of measurement standards, and data on the properties of well-characterized materials needed by industry, commerce, educational institutions, and Government; develops, produces, and distributes standard reference materials; relates the physical and chemical properties of materials to their behavior and their interaction with their environments; and provides advisory and research services to other Government agencies. The Institute consists of an Office of Standard Reference Materials and the following divisions:

Analytical Chemistry-Polymers-Metalturgy_Inorganic Materials-Physical Chemistry. THE INSTITUTE FOR APPLIED TECHNOLOGY provides technical services to promote the use of available technology and to facilitate technological innovation in industry and Government; cooperates with public and private organizations in the development of technological standards, and test methodologies; and provides advisory and research services for Federal, state, and local government agencies. The Institute consists of the following technical divisions and offices:

Engineering Standards-Weights and Measures - Invention and Innovation - Vehicle Systems Research-Product Evaluation-Building Research-Instrument Shops-Measurement Engineering-Electronic Technology-Technical Analysis.

THE CENTER FOR RADIATION RESEARCH engages in research, measurement, and application of radiation to the solution of Bureau mission problems and the problems of other agencies and institutions. The Center consists of the following divisions:

Reactor Radiation-Linac Radiation-Nuclear Radiation-Applied Radiation.

THE CENTER FOR COMPUTER SCIENCES AND TECHNOLOGY conducts research and provides technical services designed to aid Government agencies in the selection, acquisition, and effective use of automatic data processing equipment; and serves as the principal focus for the development of Federal standards for automatic data processing equipment, techniques, and computer languages. The Center consists of the following offices and divisions:

Information Processing Standards-Computer Information - Computer Services - Systems Development-Information Processing Technology.

THE OFFICE FOR INFORMATION PROGRAMS promotes optimum dissemination and accessibility of scientific information generated within NBS and other agencies of the Federal government; promotes the development of the National Standard Reference Data System and a system of information analysis centers dealing with the broader aspects of the National Measurement System, and provides appropriate services to ensure that the NBS staff has optimum accessibility to the scientific information of the world. The Office consists of the following organizational units:

Office of Standard Reference Data-Clearinghouse for Federal Scientific and Technical Information :-Office of Technical Information and Publications-Library-Office of Public Information-Office of International Relations.

1 Headquarters and Laboratories at Gaithersburg. Maryland, unless otherwise noted : mailing address Washington, D.C. 20234. 
Nat. Bur. Stand. (U.S.), Tech. Note 490, 23 pages (Aug. 1969) CODEN: NBTNA

\title{
Thermal Gradient Effects on Thirteen Flush Mounted Pressure Transducers
}

\author{
Leon Horn
}

Electronic Technology Division Institute for Applied Technology National Bureau of Standards

Washington, D.C. 20234

NBS Technical Notes are designed to supplement the Bureau's regular publications program. They provide a means for making available scientific data that are of transient or limited interest. Technical Notes may be listed or referred to in the open literature.

For sale by the Superintendent of Documents, Government Printing Office Washington, D.C.. 20402 - Price 30 cents 
1. Introduction .................... 1

2. Test Equipment . . . . . . . . . . . . . 2

3. Test Program . . . . . . . . . . . . . . 3

4. Test Results.................... 3

5. Analysis ................... 5

6. Effective Gradient Sensitivity . . . . . . . . . . 6

7. General Comments .................. . 6

8. Summary .. . . . . . . . . . . . . . . 7

\section{List of Tables}

Table 1: Oil Canning . . . . . . . . . . . . . . . . . . 9

Table 2: Thermal Gradient Response . . . . . . . . . . . 10

Table 3: Effective Thermal Gradient . . . . . . . . . . . 11

Tab1e 4: Response To Thermal Gradients . . . . . . . . . . 13

\section{List of Figures}

Figure 1: Thermal Gradient Test System . . . . . . . . . . 14

Figure 1A: Gradient Heater . . . . . . . . . . . . 15

Figures 2 through 7: Therma1 Gradient Response . . . . . . .16-21 


\section{Leon Horn}

Thirteen different flush mounted pressure transducers of seven manufacturers were tested by creating a thermal gradient in them and recording the resultant zero shifts. Photographs of typical outputs are shown and the results are compared. A typical recording shows these general characteristics; 1 . a very rapid change in output reaching a peak in a second or less, 2. a more gradual shift which reaches a peak in a time which may be a few seconds or more than a minute, and 3 . a shift in reading which remains as long as the gradient is maintained. Examples were found in which each of these were positive or negative. The magnitude in a few cases was sma11, in many was a large fraction of its range, and in one case well in excess of the full scale range.

KEY WORDS: Temperature, thermal gradients, pressure transducers, response, zero shift, pressure measurement errors.

\section{Introduction}

The effects of thermal gradients on the zero outputs of thirteen commercial pressure transducers have been studied. I Since the total number of transducers studied is not sufficient for a statistical evaluation, nor any segment large enough to be representative of a type of transducer or of a particular manufacture's transducers, the results are only indicative of the range of performance that may be encountered. We have studied transducers of similar design but of different manufacture as well as those of different design of the same manufacture.

To provide the user with a basis for judging whether a particular pressure transducer will meet the requirement of his application, the transducer manufacturer specifies the performance of the instrument over a range of temperature in which valid results may be expected. Effects of temperature on sensitivity and on zero-pressure response are usually specified. In the majority of transducers a shift of the zero-pressure response equal or less than $0.02 \%$ of full scale per degree Fahrenheit is specified.

Customarily these specifications of temperature-range performance of pressure transducers refer to equilibrium conditions, that is, to conditions in which temperature is uniform throughout the transducer. In standard temperature tests as recommended by the Instrument Society

${ }^{1}$ Response of Flush Diaphragm Pressure Transducers to Thermal Gradients Preprint No. 13,3-4-65 ISA 1965. 
of America one waits for a constant temperature to be established within the transducer before recording its output. Since equilibrium conditions do not always exist at the time of measurement in many applications, the validity of this type of temperature test alone to determine the temperature performance characteristics of pressure transducers is open to question. One can expect to find variations in temperature occurring during the measurement process, often caused by the same process that produces the pressure being measured.

A change in temperature can alter the output of a pressure transducer by changing its damping and thus its dynamic response; by altering its sensitivity and thus its output; by altering its zero-pressure output and thus the calibration base line. The study reported here investigated the influence of thermal gradients on the zero response of pressure transducers as distinct from those of changes in uniform temperature. Conditions of observation were such that no part of the instrument was exposed to a temperature greater than its proper operating range.

A word of caution should be noted. For instruments of the type tested (the flush mounted diaphragm pressure transducer) one could be dealing with the effects on the output due to: (1) A steady state gradient through the instrument. This is encountered in high speed aircraft by instruments installed between the cooled interior and the exterior which is heated by air friction; also by instruments installed near the engines of conventional aircraft (the gradient can be in any direction), or (2) A changing ambient temperature uniform in space; this, because the various components of the instrument follow the temperature change with different lags. In addition, even though an instrument has been designed to cope with both of the above conditions it still has to cope with changes with time in the gradient of temperature in the instrument, and or (3) Short term non-steady-state gradients in the environment. (Caused in many cases by the phenomena that is generating the pressure being measured.) While these tests are specifically aimed at conditions of temperature gradients in one particular direction, for gradients in different directions one can expect comparable effects and they should be investigated by the user.

\section{Test Equipment}

To evaluate the effects of thermal gradients on pressure transducers, a device capable of establishing thermal gradients in flush mounted pressure transducers was built.

An electric soldering iron was altered to serve as the heat source for generating gradients. Heat is transferred to the transducer by conduction through the thermal contact of the converted iron with a pool of molten Wood's metal. With the addition of an insulation shield and means for measuring and controlling heat output, the converted iron was found capable of transfer of $35 \mathrm{~kW} / \mathrm{m}^{2}$ at $\left(107^{\circ} \mathrm{C}\right) 225^{\circ} \mathrm{F}$ and $318 \mathrm{~kW} / \mathrm{m}^{2}$ at $\left(482^{\circ} \mathrm{C}\right)$ $900^{\circ} \mathrm{F}$. During a run, the temperatures of al1 the major components of the 
test are continuously monitored, and the thermal output of the heater can be altered by adjusting the input voltage to the heater.

Figure 1 shows the test assembly. The pressure transducer can be seen at (A). It is held by an insulated clamp (B). During the test its surface is just immersed in the liquid Wood's metal pool (C) which is used as heat transfer medium. The heater voltage is controlled by an adjustable autotransformer (D). Thermocouples (E) are used to measure the temperature of the Wood's metal and of the front and back surfaces of the transducer. A recorder is used to keep multiple continuous records of temperatures during the test. The electrical output of the transducer is displayed on an oscilloscope and photographed.

\section{Test Program}

Each transducer was first checked using the standard series of uniform temperature tests ${ }^{2}$ in order to compare its performance with that listed in the manufacturer's specifications; a11 were found to be within specifications.

The gradient test produces a temperature gradient within the pressure transducer with the high temperature region at the pressure sensing end. In a typical test series the temperature of the heat source was increased in steps, running one test at each step, until the specified limiting operating temperature of the transducer was reached. The temperature of the sensing end and the back of transducer and the zero level output were recorded during each run.

The tests to date have been limited to a maximum front surface temperature of $600^{\circ} \mathrm{F}\left(315.5^{\circ} \mathrm{C}\right)$. A heat influx of approximately 225 $\mathrm{kW} / \mathrm{m}^{2}$ was required to achieve this temperature.

\section{Test Results}

A typical thermal gradient zero shift curve from a flush diaphragm type pressure transducer, Figure 2 (a), shows the following:

1. A very rapid change in output reaching a peak in a second or less (in this instance a negative peak value).

2. A more gradual shift which reaches a peak in a time which may be a few seconds or more than a minute.

3. A shift in zero reading which tends to level off toward some value which may remain as long as the gradient is maintained. In this instance the maximum zero shift was not in the same direction as the initial peak shift.

${ }^{2}$ NBS Technical Note \#411, February 9, 1967, Methods for PerformanceTesting of Electromechanical Pressure Transducer, P. S. Lederer. 
The initial portion of the curve has been interpreted as "oil canning," the differential expansion and "popping" of a diaphragm held by a rigid hoop. In general, this is observed as a rapid response, i.e., "oil canning" can occur in less than one second. It varied from $+2.0 \%$ FS (full scale) to $-30 \%$ FS and appeared to be least in those instruments that showed the smallest zero shift.

Figures $2 \mathrm{a}$ and $2 \mathrm{~b}$ show the effect of what is being called "oil canning" in the output of two different transducers. Figure $2 \mathrm{~b}$ shows an unusually large effect. It, and the maximum zero shift are closely related in this instance and represent the largest response of the kind observed. Figure $3 \mathrm{a}$ is included to show the possible response speed of such behavior. For this transducer, a piezoelectric type, a change of $1.9 \%$ FS (in this instance, $332 \mathrm{kN} / \mathrm{m}^{2}$ ) occurred in a fraction of a second.

The photographs of the shifts of the zero level outputs of the various transducers have been given effective gradient numbers which represent the transducer's position in the ordered sequence of effective gradient sensitivities. The photographs represent typical zero-shifts and were not chosen for maximum test conditions. The test temperature is given alongside each photograph. It was noted that while duplicate transducers tested (Figure 3, photographs (b) and (c) same model series number and range) under duplicate conditions gave similar results, some units of the same manufacturer and same series but of different pressure ranges did not. (Figure 4, photographs (a), (b), and (c) are of the same model series but of different ranges.)

On all the transducers tested, as long as a gradient existed, a zero shift was observed and a zero shift steady state condition could be approached. Photos, Figures $6 \mathrm{a}, 6 \mathrm{~b}$, and $6 \mathrm{c}$, are particular examples of this condition.

Excluding the initial pulse, a separation of the thirteen observations into two patterns can be noted. The division is between those whose zero shift maximizes within the test period and those tending to show a gradual increase with time (see remarks in Table 4). Since maxima were observed only in compensated transducers, it is suggested that placement of the temperature compensating elements may be responsible.

The maximum zero shifts and response time of the different transducers are listed in Table 4. It was noted that an increase in the rate of heating from $35 \mathrm{~kW} / \mathrm{m}^{2}$ to $350 \mathrm{~kW} / \mathrm{m}^{2}$ did not alter the time required to reach maximum zero shift in the tests, although the increase did alter the gradient and the magnitude of maximum zero shift.

A review of the data taken during all the tests indicated that the gradient induced during a particular transducer test is related to the temperature of the hot pool with which the transducer is in contact and the length of time it has been immersed. The numerical value of the maximum zero shift thus depends to a great extent of the test conditions. 


\section{Analysis}

An example of the analysis of one particular transducer involving an intermediate rate of thermal gradient is as follows. The empirical relationship, $Z=A^{\circ} \cdot \mu+X_{j}\left(A^{\circ}-B^{\circ}\right)$, was found to hold for the conditions over which flush mounted pressure transducers were tested.

$$
\begin{aligned}
& \text { where } Z=\text { zero output as } \% \text { FS, } \\
& \text { where } \mu=\text { manufacturer's thermal coefficient per degree, } \\
& \text { where } A=\text { temperature of front surface of the transducer, } \\
& \text { where } B=\text { temperature of back exposed surface of the transducer, } \\
& \text { and } X_{j}=\begin{array}{l}
\text { correction coefficient for the specific condition of } \\
\text { the test and particular transducer }(j) .
\end{array}
\end{aligned}
$$

In order to find the numerical value of the correction coefficient $X$ for a particular pressure transducer, one makes a gradient temperature run with the transducer held at a measured temperature $A$ at the active front surface, and records the temperature $B$ of the exposed back surface and the zero pressure level output of the transducer. The values of $A, B$ and the manufacturer's specification for zero output as a function of operating temperature is then used in the equation. One solves for $X$.

One assumes that if tile experimental setup is similar to that expected in the intended test, the value of $X$ derived can be used to determine the percent of full scale zero shift that will occur under the thermal condition of the actual test. Although the value of $x$ derived was determined by the average of five points taken during one previous run, Table 2 is composed of data from six different runs picked because they provided examples of differences in operating procedures that covered the entire testing temperature range and measured zero shift. Run number 1 was made on a unit which initially was slightly above room temperature and cooled by convection, i.e., no provision being provided for additional air cooling. Runs numbered 2, 3, and 5 were initially at room temperature and cooled by convection currents. Runs numbered 4 and 6 were initially at room temperature and were cooled by forced air. A fan directed room air on the exposed back of the transducer during the test.

The relationship \% FS zero shift $=A$. (manufacturer's coefficient per degree $)+X(A-B)$ is based on the limited data taken from the thermal gradient measurements of thirteen different transducers. It is limited in use to the zero shift after oil canning for various conditions of front surface temperatures and resultant temperature gradients. It was found to be correct to $\pm 10 \%$ for the flush diaphragm pressure transducers tested.

The following example illustrates the procedure to be followed in using the correction for a transducer under test. In this instance, temperatures in ${ }^{\circ} \mathrm{F}$ are used to conform to the customary practice of 
manufacturers in publishing transducer specifications. The empirical relationship found for the gage of Figure $2 \mathrm{c}$ was $0.02 \% \mathrm{FS} /{ }^{\circ} \mathrm{F}$ (manufacturer's specification) plus $0.30 \% \mathrm{FS} /{ }^{\circ} \mathrm{F}$ (thermal transient test, correction coefficient derived). One would therefore multiply 0.02 by the temperature $A$ of the front surface and then add the differential term 0.30 (A - B) where B is the temperature of the back surface of the transducer. One would then convert from $\%$ FS to psi and subtract this value from the recorded pressure. The result would be the pressure $\pm 10 \%$, that would have been recorded if no thermal gradient had existed. In this way correction is made for the zero shift of the transducer after the first few seconds, provided the front and back temperatures of the transducer have been monitored. An additional correction may be necessary due to a change in sensitivity with temperature, although the error from this source was not important in the devices that have been tested.

\section{Effective Gradient Sensitivity}

In order to allow comparisons among transducers tests at different temperatures and with resultant different gradients, a relative "effective gradient sensitivity," (EGS) was calculated. The effective gradient sensitivity was defined by dividing the maximum zero shift, in percent of full scale, by the temperature difference between the hotter surface of the transducer and the reference temperature for zero shift of the transducer. The results are listed in Table 3 in terms of $\% \mathrm{FS} /{ }^{\circ} \mathrm{F}$ and $\% \mathrm{FS} /{ }^{\circ} \mathrm{C}$.

Since all the transducers were given the same kind of test, in each case to the limit of the expected normal operating temperature, these values (EGS) represent a measure of ability to perform while exposed to thermal gradients. A transducer that has an EGS value that is equal to or less than the manufacturer's specifications for zero shift with temperature can be considered to be unaffected by thermal gradients.

\section{General Comments}

As indicated in the earlier study ${ }^{3}$ and verified by the tests reported here, design differences can be more important than the kind of active element used in the transducer. Although both of the manufacturers of the two pressure transducers used to obtain the test results shown in Figures 4 and 5 used unbonded strain gages as their active elements, the zero-shift response to thermal gradients differed widely.

The photographs in Figures $5 \mathrm{a}$ and $5 \mathrm{~b}$ show the results of thermal gradient tests on two transducers produced by the same manufacturer eleven years apart. During this time, 1954 to 1965, the specification

${ }^{3} 1$ oc cite. 
for the upper operating temperature limit changes from $165^{\circ} \mathrm{F}$ to $250^{\circ} \mathrm{F}$ and the zero shift specification was reduced from 0.08 to $0.015 \% \mathrm{FS} /{ }^{\circ} \mathrm{F}$.

Some of the factors that govern the effect of a temperature gradient are: the mass of the section exposed to the heat, i.e., the thermal inertia of the case, the thermal path differences that exist between the active elements and the compensating elements, the thermal alterations of strain members, and changes in spring positions due to temperature gradients in the supports. In addition, one could expect zero shifts to result from "oil canning," leverage shifts due to unequal expansion of parts, and variations in electrical and physical properties with temperature. These factors need to be considered in attempting to reduce or avoid the effect of thermal gradients.

To avoid the zero shift that is due to deformation requires a design that allows for the thermal differences that are expected or are possible. Balanced and compensated mechanical motions and thermal buffers for sensitive springs and flexures are possibilities. Fused Quartz or sapphire rods for extensions to provide relatively constant dimensions and still provide poor conduction of the heat would seem to be one way of removing the active elements of the transducer from the immediate vicinity of the heat source, thus producing a relatively constant environment that tends to isolate and protect the active elements for short period of time.

One can transmit the pressure to be measured by tubes to a cooler region (with altered dynamic characteristics), or cool the active elements of the transducer by external means.

A compromise that would provide the equivalent of a uniform temperature zone for the transducer would consist of uniformly preheating the transducer to within a few degrees of the expected working temperature just before the test.

\section{Summary}

Studies of the effects of thermal gradients on performance of pressure trandducers indicate that: 1. Flush diaphragm pressure transducers may show very large zero shifts due to thermal gradients even though they are compensated for changes in uniform temperatures. 2. For the thirteen units tested, the detailed design is as important as the principle used to convert diaphragm deflection to an electrical output signal, i.e., piezoelectric crystal, wire strain gages, bonded or not, differential transformer, etc. 3. Some transducers can operate in a thermal gradient with very little zero shift, but no simple way to predict this without testing is apparent at this time.

Since the transducer's zero shift in this test is the result of an imposed thermal gradient and is a function of the transducer design, a comparison of responses to thermal gradients reflects the comparison of transducer design features. 
For the transducers tested, although the rate of energy input and thermal flux density influenced the magnitude and the time to reach a given gradients, it is the temperature gradient itself that is responsible for the zero shift of the instrument and this should be considered when choosing a pressure transducer for field use.

The wide range of response that was encountered in these tests emphasized the need for caution in interpreting the data furnished by pressure transducers when thermal gradients may be present. While these tests specifically aimed at conditions of temperature gradients in one particular direction, for gradients in other directions one can expect comparable effects and they should be investigated by the user. 
TABLE 1

Oi 1 Canning

Transducer Type

Pressure

Range

$\%$ FS

Time to Reach

Maximum

(Seconds)

(A) Unbonded wire strain
gages (damped and un-

$0-300$

$-1.0$

8.0

damped)

Unbonded wire strain

$0-1000$

$-3.0$

8.0

gages (damped and undamped)

Unbonded wire strain

$0-50$

$-1.0$

1.0

gages (damped and un-

damped)

Unbonded wire strain

$0-15$

$-30.0$

2.0

gages (damped and undamped)

(B) Bonded strain gages

damped

$0-500$

$-8.0$

1.0

(C) Semiconductor strain gages

Semiconductor strain

$0-100$

$+1.8$

1.0

gages

(D) Unbonded strain gage

$0-150$

$-23.0$

1.0

Unbonded strain gage

$0-50$

$-10.0$

0.1

(E) Variable inductance

$0-100$

$-2.5$

1.5

Variable inductance

$0-100$

$-5.0$

1.5

(F) Linear differential

$0-500$

none noted

trans former

(G) Crysta1

$0-3000$

$-1.8$

0.1 
TABLE 2

Thermal Gradient Response

Zero Shift
$\%$ FS

Temperature Front Measured

(A) $228^{\circ} \mathrm{F}$ $180^{\circ} \mathrm{F}$ $300^{\circ} \mathrm{F}$ $253^{\circ} \mathrm{F}$ $545^{\circ} \mathrm{F}$ $360^{\circ} \mathrm{F}$
Temperature Differential Measured

$$
\text { (A-B) }
$$

60

120

120

160
Computed

$0.02(A)+0.3(A-B)$

19

23

24

41

47

55
Measured

18

25

25

44

49

50 
TABLE 3

Effective Thermal Gradient

\begin{tabular}{|c|c|c|c|c|c|c|}
\hline \multirow[t]{2}{*}{$\begin{array}{l}\text { Figure } \\
\text { Number }\end{array}$} & \multirow[t]{2}{*}{ Transducer Type } & \multirow{2}{*}{$\begin{array}{l}\text { Pressure } \\
\text { Range } \\
\text { PSI }\end{array}$} & \multicolumn{2}{|c|}{ EGS } & \multicolumn{2}{|c|}{$\begin{array}{l}\text { Manufacturer's } \\
\text { Specifications }\end{array}$} \\
\hline & & & $\% \mathrm{FS} /{ }^{\circ} \mathrm{F}$ & $\% \mathrm{FS} /{ }^{\circ} \mathrm{C}$ & $\% \mathrm{FS} /{ }^{\circ} \mathrm{F}$ & $\% \mathrm{FS} /{ }^{\circ} \mathrm{C}$ \\
\hline $4 a$ & $\begin{array}{l}\text { Unbonded wire } \\
\text { strain gages } \\
\text { (damped and } \\
\text { undamped) }\end{array}$ & $0-300$ & 0.004 & 0.007 & 0.01 & 0.018 \\
\hline $4 b$ & $\begin{array}{l}\text { Unbonded wire } \\
\text { strain gages } \\
\text { (damped and } \\
\text { undamped) }\end{array}$ & $0-1000$ & 0.01 & 0.02 & 0.01 & 0.018 \\
\hline 7 & $\begin{array}{l}\text { Semiconductor } \\
\text { strain gages }\end{array}$ & $0-100$ & 0.01 & 0.02 & 0.01 & 0.018 \\
\hline 6 & $\begin{array}{l}\text { Variable } \\
\text { Inductance }\end{array}$ & $0-100$ & 0.018 & 0.03 & 0.01 & 0.018 \\
\hline 3 & Crystal & $0-3000$ & 0.03 & 0.05 & 0.01 & 0.018 \\
\hline $3 b \& c$ & $\begin{array}{l}\text { Bonded strain } \\
\text { gages damped }\end{array}$ & $0-500$ & 0.043 & 0.08 & 0.01 & 0.018 \\
\hline 6 & $\begin{array}{l}\text { Linear } \\
\text { Differential } \\
\text { Transformers }\end{array}$ & $0-500$ & 0.073 & 0.13 & none & \\
\hline 2 & $\begin{array}{l}\text { Unbonded } \\
\text { strain } \\
\text { gages }\end{array}$ & $0-150$ & 0.083 & 0.15 & 0.02 & 0.036 \\
\hline $5 b$ & $\begin{array}{l}\text { Unbonded wire } \\
\text { strain gages } \\
\text { (damped and } \\
\text { undamped) }\end{array}$ & $0-50$ & 0.10 & 0.18 & 0.015 & 0.018 \\
\hline $5 a$ & $\begin{array}{l}\text { Unbonded wire } \\
\text { strain gages } \\
\text { (damped and } \\
\text { undamped) }\end{array}$ & $0-50$ & 0.14 & 0.15 & 0.04 & 0.072 \\
\hline
\end{tabular}


TABLE 3 (Continued)

\begin{tabular}{|c|c|c|c|c|c|c|}
\hline \multirow{2}{*}{$\begin{array}{l}\text { Figure } \\
\text { Number }\end{array}$} & \multirow[t]{2}{*}{ Transducer Type } & \multirow{2}{*}{$\begin{array}{l}\text { Pressure } \\
\text { Range } \\
\text { PSI }\end{array}$} & \multicolumn{2}{|c|}{ EGS } & \multicolumn{2}{|c|}{$\begin{array}{l}\text { Manufacturer's } \\
\text { Specifications }\end{array}$} \\
\hline & & & $\% \mathrm{FS} /{ }^{\circ} \mathrm{F}$ & $\% \mathrm{FS} /{ }^{\circ} \mathrm{C}$ & $\% \mathrm{FS} /{ }^{\circ} \mathrm{F}$ & $\% \mathrm{FS} /{ }^{\circ} \mathrm{C}$ \\
\hline $2 b^{*}$ & $\begin{array}{l}\text { Unbonded wire } \\
\text { strain gages } \\
\text { (damped and } \\
\text { undamped) }\end{array}$ & $0-15$ & 0.16 & 0.19 & 0.01 & 0.018 \\
\hline $4 c^{*}$ & $\begin{array}{l}\text { Unbonded wire } \\
\text { strain gages } \\
\text { (damped and } \\
\text { undamped) }\end{array}$ & $0-50$ & 0.50 & 0.9 & 0.01 & 0.018 \\
\hline
\end{tabular}

Figure 5a Received 1954 Figure 5b Received 1965

*The last two transducers require special mention. The 0-15 PSI gage did return to manufacturer's specifications during the test within 50 seconds after the introduction of heat. The 0-50 PSI appears to have a loose connection which separated under the stresses developed by a thermal gradient. The transducer did not show any abnormal output for any of the standard tests and checked out within the manufacturer's specifications in the normal temperature tests, both before and after the thermal gradient tests. (See photographs $2 \mathrm{~b}$ and $4 \mathrm{c}$.) 
Response To Thermal Gradients

$\begin{array}{cccccc}\text { Transducer } & \text { Pressure } & \text { Test } & \text { Maximum } & \text { Time at } & \text { Remarks } \\ \text { Type } & \text { Range } & \text { Temperature } & \text { Zero } & \text { Which } & \\ & \text { PSI } & { }^{\circ} \text { F } & \text { Shift } & \text { Maximum } & \\ & & \% \text { FS } & \text { Occurs in } & \text { Seconds }\end{array}$

\begin{tabular}{|c|c|c|c|c|c|}
\hline \multirow[t]{5}{*}{ A } & $0-15$ & 200 & -32 & $1-3$ & Recovers to less than \\
\hline & $0-50$ & 230 & $>+100$ & 30 & $\begin{array}{l}\text { After peak goes off } \\
\text { scale requires } 10 \\
\text { minutes to recover }\end{array}$ \\
\hline & $0-300$ & 212 & +1.0 & 50 & $\begin{array}{l}\text { After peak at } 50 \text { sec- } \\
\text { onds recovery starts }\end{array}$ \\
\hline & $0-1000$ & 400 & +4.0 & $180 * *$ & $\begin{array}{l}\text { Maximum shift in- } \\
\text { creases with time }\end{array}$ \\
\hline & $0-500$ & 600 & -26 & 20 & After peak \\
\hline B & $0-500$ & 600 & -26 & 20 & $\begin{array}{l}\text { After peak at } 20 \mathrm{sec}- \\
\text { onds recovery starts }\end{array}$ \\
\hline \multirow[t]{2}{*}{$\mathrm{C}$} & $0-100$ & 190 & -2.0 & 31 & \multirow[t]{2}{*}{$\begin{array}{l}\text { After peak at } 31 \text { sec- } \\
\text { onds recovery starts }\end{array}$} \\
\hline & $0-100$ & 190 & -2.0 & $81^{*}$ & \\
\hline \multirow[t]{3}{*}{ D } & $0-150$ & 600 & +49 & 51 & $\begin{array}{l}\text { After peak at } 51 \text { sec- } \\
\text { onds recovery starts }\end{array}$ \\
\hline & $0-50$ & 160 & +22 & 10 & $\begin{array}{l}\text { After peak at } 10 \mathrm{sec}- \\
\text { onds recovery starts }\end{array}$ \\
\hline & $0-50$ & 250 & +26 & 8 & $\begin{array}{l}\text { After peak at } 8 \text { sec- } \\
\text { onds recovery starts }\end{array}$ \\
\hline E & $0-100$ & 250 & +6.0 & $180 * *$ & $\begin{array}{l}\text { Maximum shift in- } \\
\text { creases with time }\end{array}$ \\
\hline $\mathrm{F}$ & $0-500$ & 320 & +23 & $180 * *$ & $\begin{array}{l}\text { Maximum shift in- } \\
\text { creases with time }\end{array}$ \\
\hline G & $0-3000$ & 373 & -10 & 7 & $\begin{array}{l}\text { After a peak at } 7 \mathrm{sec}- \\
\text { onds starts to recover } \\
\text { (test was limited to } \\
20 \text { seconds) }\end{array}$ \\
\hline
\end{tabular}

*Test Limited to 81 Seconds.

**Test Limited to 180 Seconds. 


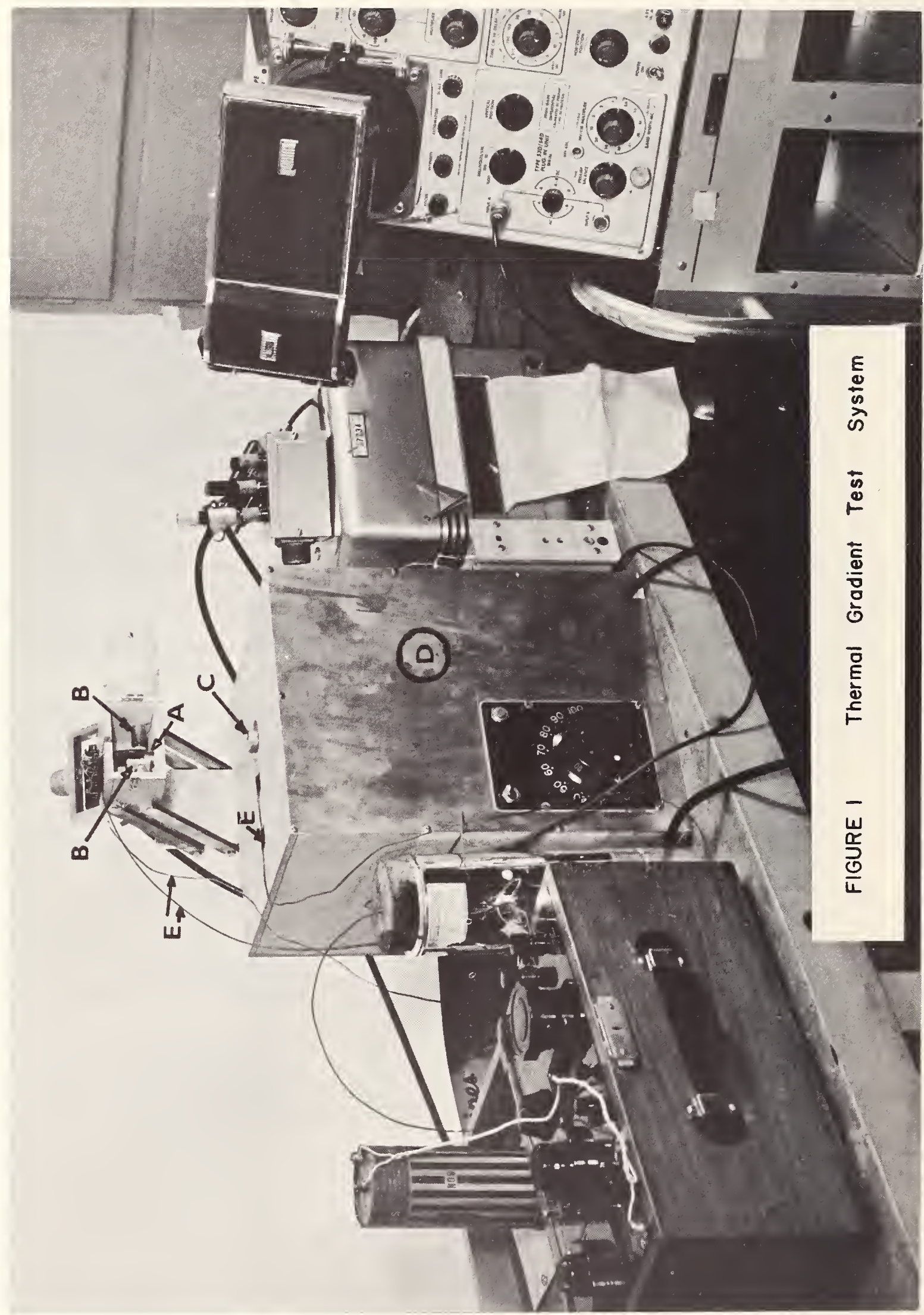



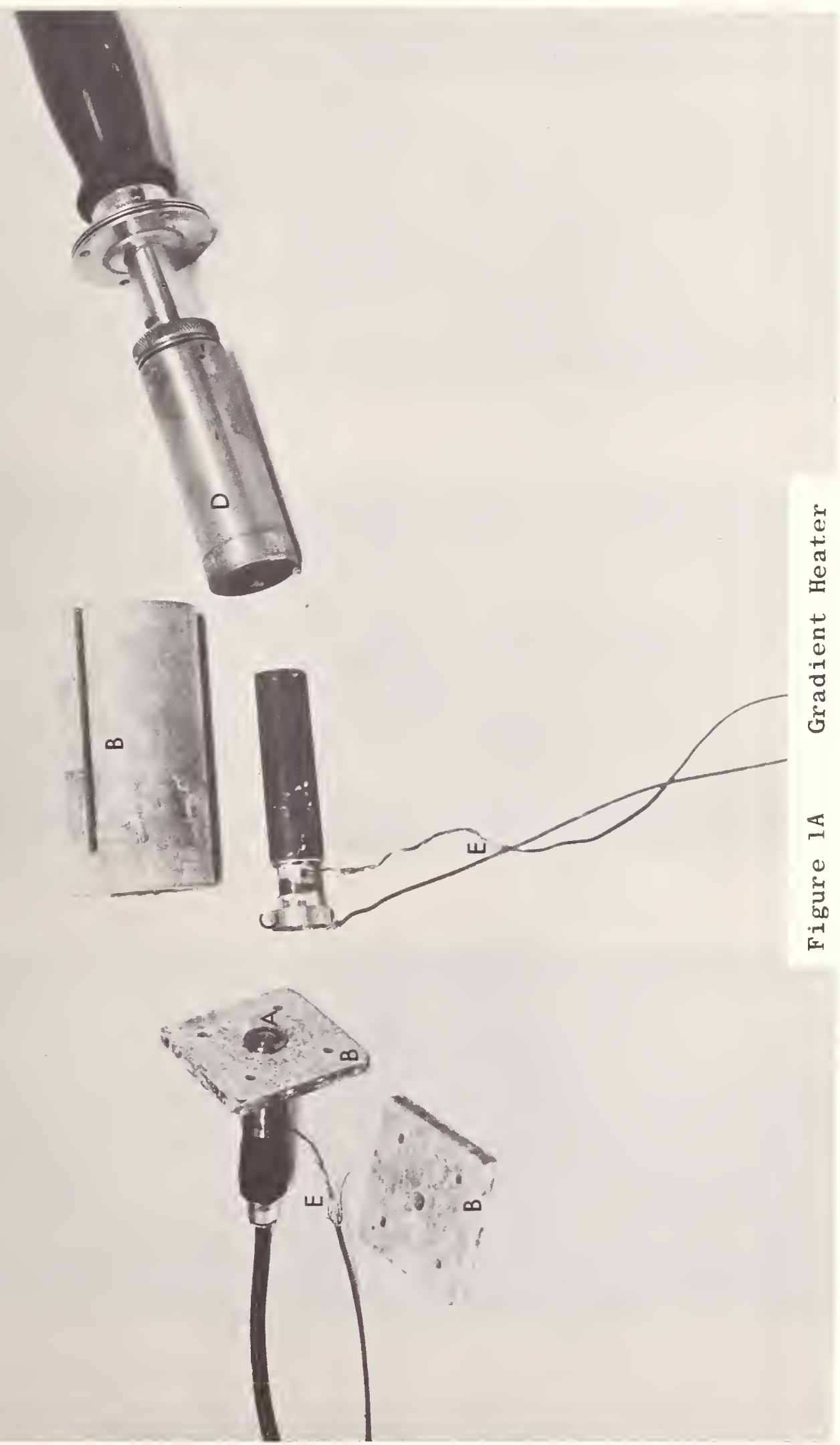


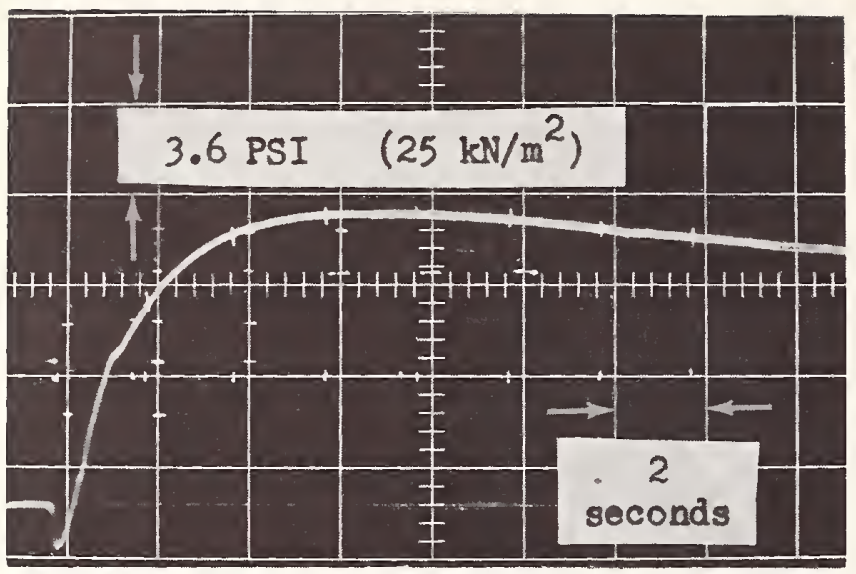

(a)

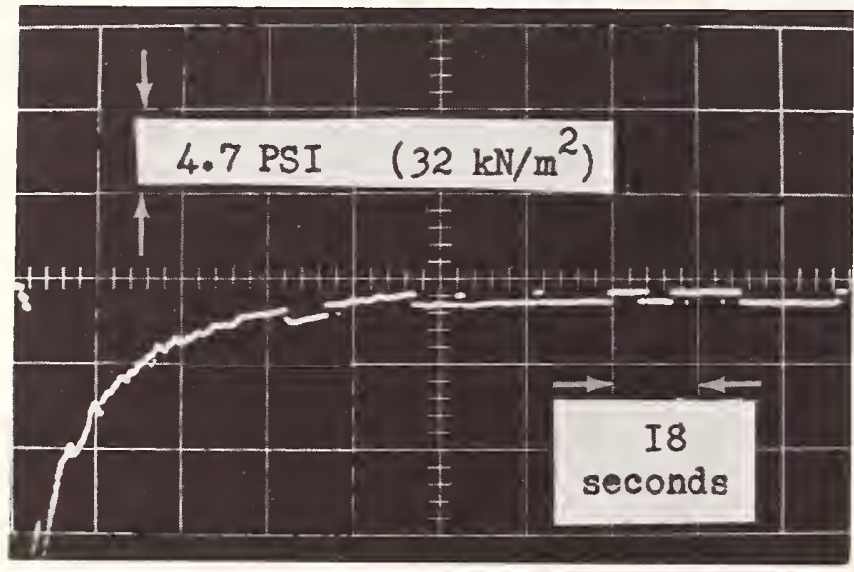

(b)

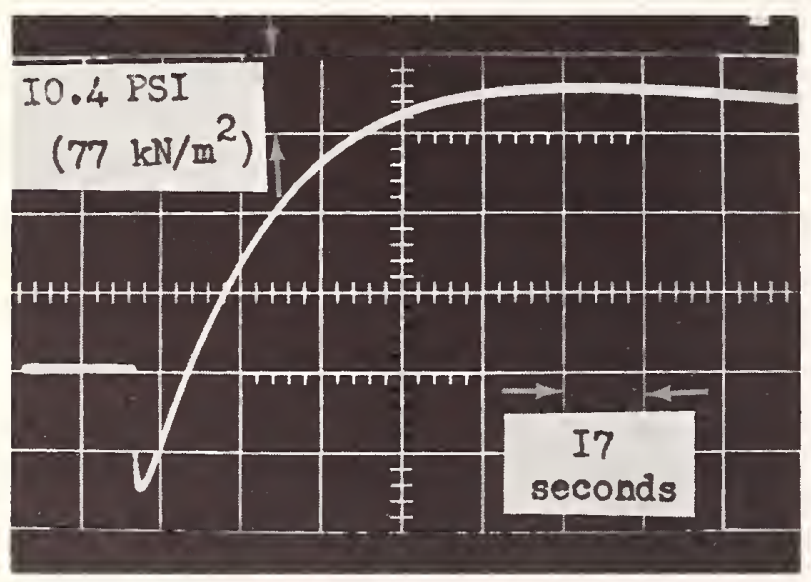

(c)
Unbonded Strain Gage $0-50$ PSI

Time $2 \mathrm{~S} / \mathrm{cm}$

Temp. $\quad 165^{\circ} \mathrm{F} \quad 74^{\circ} \mathrm{C}$

Max Zero Shift $+23 \%$ FS
Unbonded Strain Gage $0-15$ PSI

Time $\quad 18 \mathrm{~s} / \mathrm{cm}$

Temp. $\quad 200^{\circ} \mathrm{F} \quad 93^{\circ} \mathrm{C}$

Max Zero Shift - $32.7 \%$ FS
Unbonded Strain Gage $0-150$ PSI

Time $17 \mathrm{~S} / \mathrm{cm}$

Temp. $200^{\circ} \mathrm{F} \quad 93^{\circ} \mathrm{C}$

Max Zero Shift $+25 \%$ FS

Figure 2 Thermal Gradient Response 


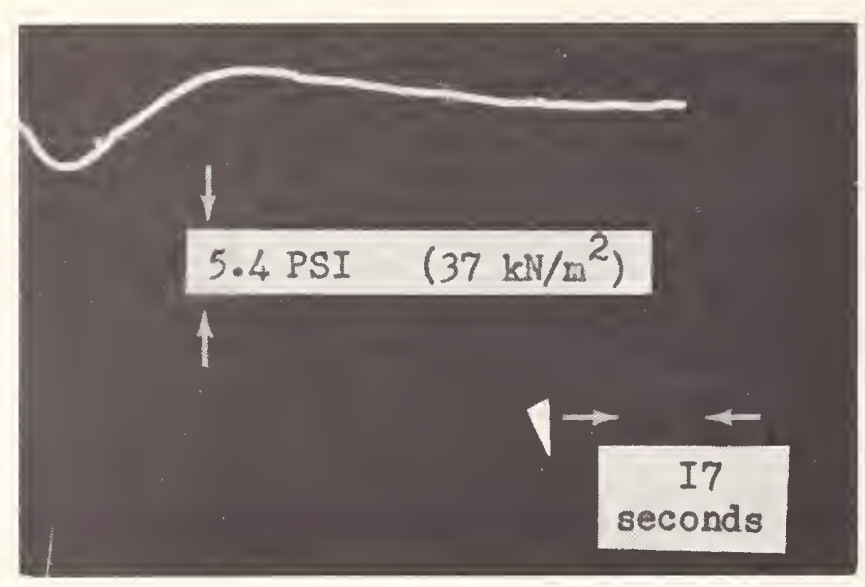

Unbonded Strain Gage Range

$0-300$ PSI

Time

$17 \mathrm{~S} / \mathrm{cm}$

Test Temp. $212^{\circ} \mathrm{F} \quad 100^{\circ} \mathrm{C}$ Max Zero Shift $1.3 \%$ FS

\section{(a)}

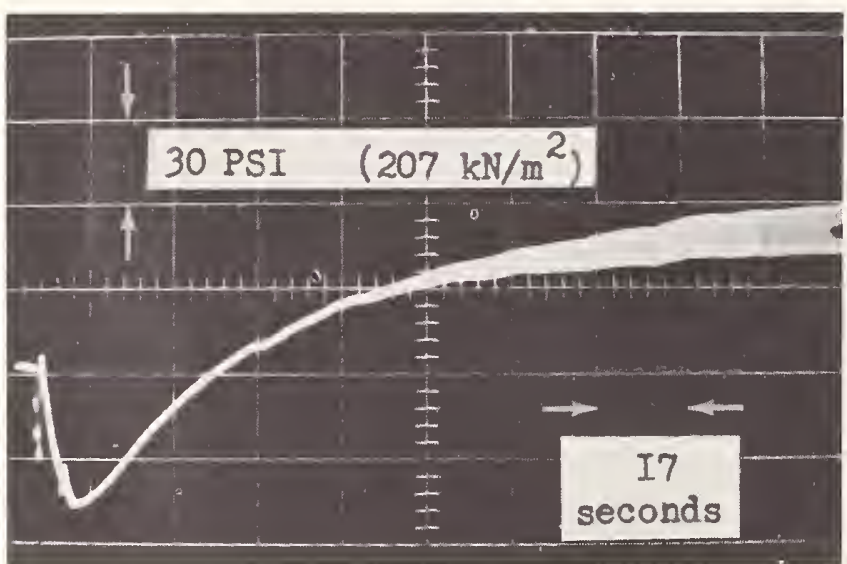

Unbonded Strain Gage Range

$0-1000$ PSI

Time

$17 \mathrm{~S} / \mathrm{cm}$

Test Temp. $400^{\circ} \mathrm{F} 204^{\circ} \mathrm{C}$ Max Zero Shift $4 \%$ FS

\section{(b)}

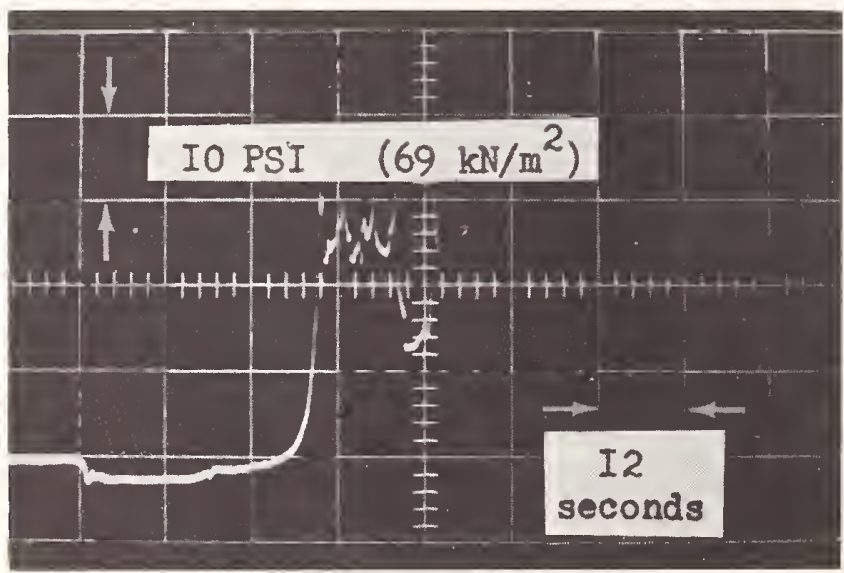

Unbonded Strain Gage Range $\quad 0-50$ PSI Time $\quad 12 \mathrm{~S} / \mathrm{cm}$ Test Temp. $230^{\circ} \mathrm{F} \quad 110^{\circ} \mathrm{C}$ Max Zero Shift $+100 \%$ FS

\section{(c)}

Figure 4 Thermal Gradient Response 


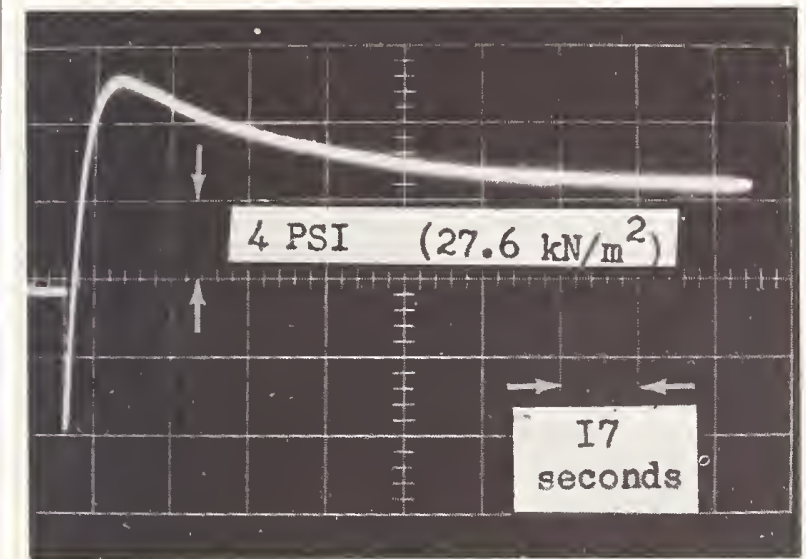

Unbonded Strain Gages

Range $\quad 0-50$ PSI

Time $\quad 17 \mathrm{~S} / \mathrm{cm}$

Test Temp. $100^{\circ} \mathrm{F} 74^{\circ} \mathrm{C}$ Max Zero Shift $23 \%$ FS

\section{(a)}

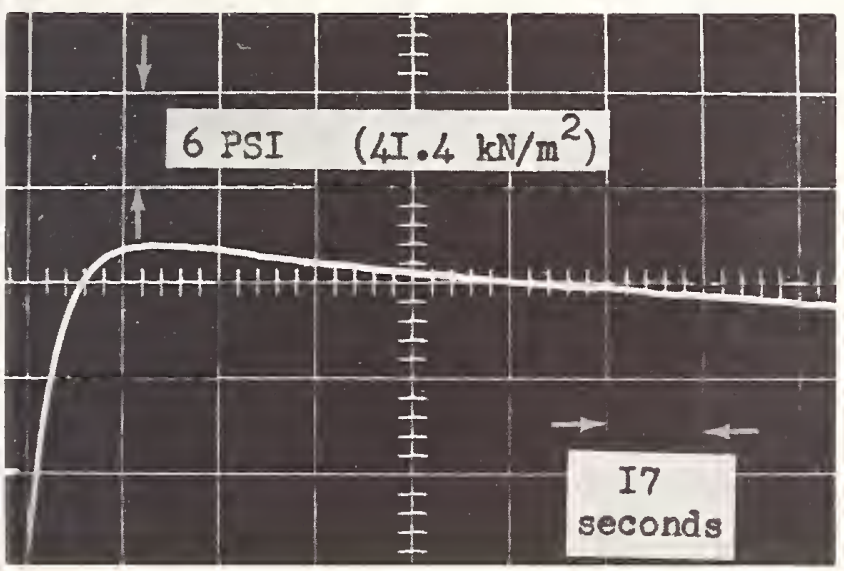

Unbonded Strain Gages

Range

0-50 PSI

Time

$17 \mathrm{~S} / \mathrm{cm}$

Test Temp. $231^{\circ} \mathrm{F} \quad 111^{\circ} \mathrm{C}$

Max Zero Shift $30 \%$ FS

(b)

Figure 5 Thermal Gradient Response 


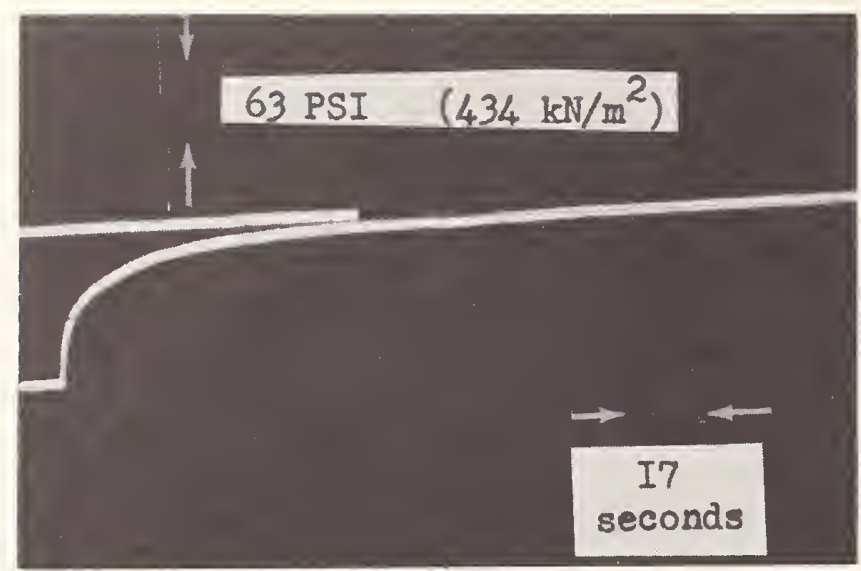

(a)

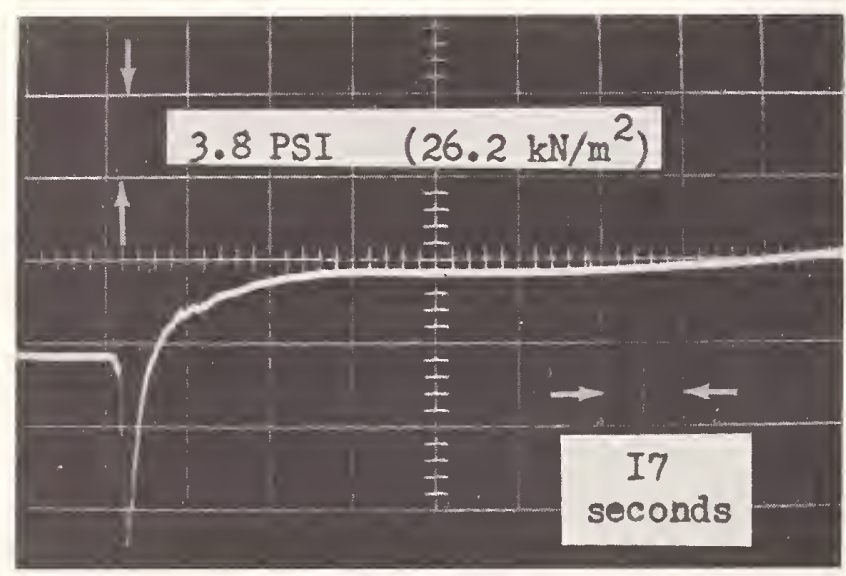

(b)

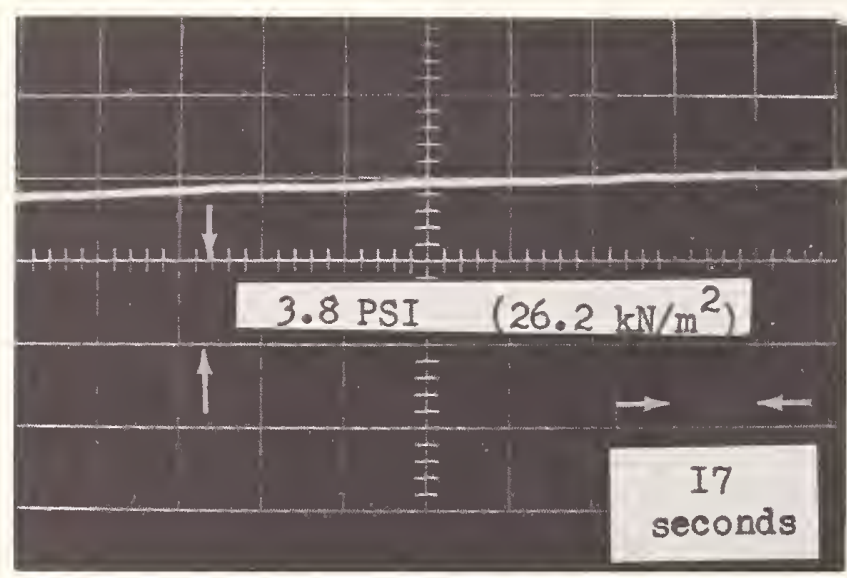

(c)
Differential Transformer Range 0-500 PSI

Time $\quad 17 \mathrm{~S} / \mathrm{cm}$

Temp. $\quad 320^{\circ} \mathrm{F} \quad 160^{\circ} \mathrm{C}$

Max Zero Shift $+23.4 \%$ FS
Variable Inductance Range 0-100 PSI

Time $17 \mathrm{~s} / \mathrm{cm}$

Temp. $\quad 250^{\circ} \mathrm{F} \quad 121^{\circ} \mathrm{C}$

Max Zero Shift $+4.5 \%$ FS

(b) 1 st 2.8 minutes
Conditions same as (b) after 12 th minute

Figure 6 Thermal Gradient Response 


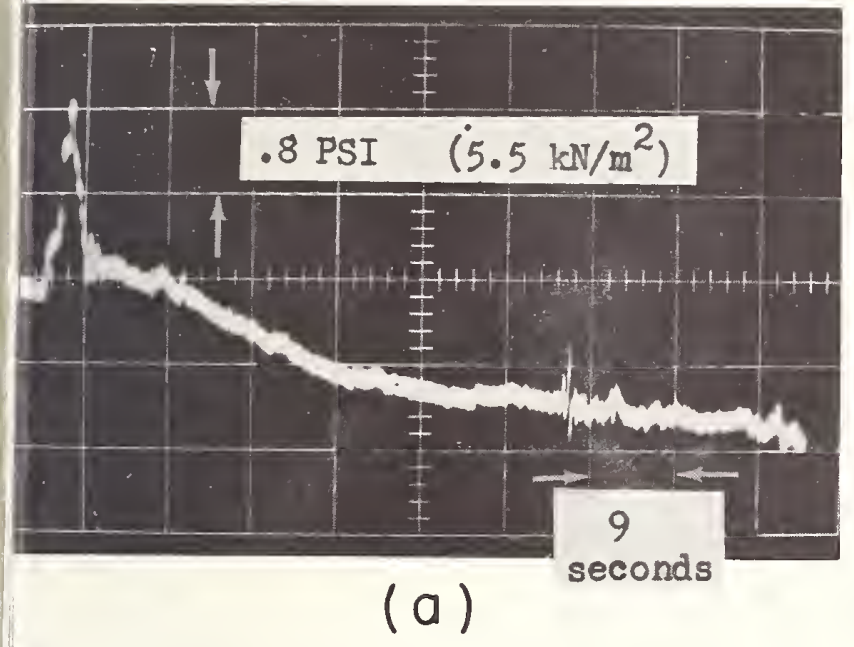

Semiconductor Gages

Range 0-100 PSI

Time $9 \mathrm{~S} / \mathrm{cm}$

Temp. $193^{\circ} \mathrm{F} \quad 89^{\circ} \mathrm{C}$

Max Zero Shift $1.9 \%$ FS

Semiconductor Gages

Range 0-100 PSI

Time $17 \mathrm{~S} / \mathrm{cm}$

Temp. $193^{\circ} \mathrm{F}$

Max Zero Shift $1.9 \%$ FS

\section{I7} seconds

(b)

Figure 7 Thermal Gradient Response 



\section{PERIODICALS}

JOURNAL OF RESEARCH reports National Bureau of Standards research and development in physics, mathematics, chemistry, and engineering. Comprehensive scientific papers give complete details of the work, including laboratory data, experimental procedures, and theoretical and mathematical analyses. Illustrated with photographs, drawings, and charts.

Published in three sections, available separately:

\section{Physies and Chemistry}

Papers of interest primarily to scientists working in these fields. This section covers a broad range of physical and chemical research, with major emphasis on standards of physical measurement, fundamental constants, and properties of matter. Issued six times a year. Annual subscription: Domestic, $\$ 9.50$; foreign, $\$ 11.75^{*}$.

\section{Mathematical Sciences}

Studies and compilations designed mainly for the mathematician and theoretical physicist. Topics in mathematical statistics, theory of experiment; design, numerical analysis, theoretical physics and chemistry, logical design and programming of computers and computer systems. Short numerical tables. Issued quarterly. Annual subscription: Domestic, $\$ 5.00$; foreign, $\$ 6.25^{*}$.

\section{Engineering and Instrumentation}

Reporting results of interest chiefly to the engineer and the applied scientist. This section includes many of the new developments in instrumentation resulting from the Bureau's work in physical measurement, data processing, and development of test methods. It will also cover some of the work in acoustics, applied mechanics, building research, and cryogenic engineering. Issued quarterly. Annual subscription: Domestic, $\$ 5.00$; foreign, $\$ 6.25^{*}$.

\section{TECHNICAL NEWS BULLETIN}

The best single source of information concerning the Bureau's research, developmental, cooperative and publication activities, this monthly publication is designed for the industry-oriented individual whose daily work involves intimate contact with science and technology-for engineers, chemists, physicists, research managers, product-development managers, and company executives. Annual subscription: Domestic, $\$ 3.00$; foreign, $\$ 4.00^{*}$.

- Difference in price is due to extra cost of foreign mailing.

\section{NONPERIODICALS}

Applied Mathematics Series. Mathematical tables, manuals, and studies.

Building Science Series. Research results, test methods, and performance criteria of building materials, components, systems, and structures.

Handbooks. Recommended codes of engineering and industrial practice (including safety codes) developed in cooperation with interested industries, professional organizations, and regulatory bodies.

Special Publications. Proceedings of NBS conferences, bibliographies, annual reports, wall charts, pamphlets, etc.

Monographs. Major contributions to the technical literature on various subjects related to the Bureau's scientific and technical activities.

National Standard Reference Data Series. NSRDS provides quantitive data on the physical and chemical properties of materials, compiled from the world's literature and critically evaluated.

Product Standards. Provide requirements for sizes, types, quality and methods for testing various industrial products. These standards are developed cooperatively with interested Government and industry groups and provide the basis for common understanding of product characteristics for both buyers and sellers. Their use is voluntary.

Technical Notes. This series consists of communications and reports (covering both other agency and NBS-sponsored work) of limited or transitory interest.

Federal Information Processing Standards Publications. This series is the official publication within the Federal Government for information on standards adopted and promulgated under the Public Law 89-306, and Bureau of the Budget Circular A-86 entitled, Standardization of Data Elements and Codes in Data Systems.

\section{CLEARINGHOUSE}

The Clearinghouse for Federal Scientific and Technical Information, operated by NBS, supplies unclassified information related to Government-generated science and technology in defense, space, atomic energy, and other national programs. For further information on Clearinghouse services, write:

Clearinghouse

U.S. Department of Commerce

Springfield, Virginia 22151 
U.S. DEPARTMENT OF COMMERCE

WASHINGTON, D.C. 20230

OFFICIAL BUSINESS

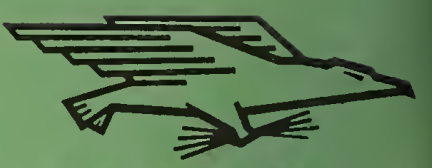

POSTAGE AND FEES PAID

U.S. DEPARTMENT OF COMMERCE 